\title{
KARL JASPERS, A HISTÓRIA COMO TOTALIDADE *
}

\author{
Karl Jaspers, history as a whole
}

José Mauricio de Carvalho **

Resumo: Esse artigo examina como Jaspers aborda a totalidade da História e a importância desta questão. Esclarece que tentativas de estabelecer tal unidade pelos fatos empíricos estão fadadas ao fracasso, porque a totalidade somente pode ser buscada como realidade espiritual, ou criação do homem. Assim considerada, tal totalidade é resultado da comunicação entre os seres humanos. Isso significa que como jornada humana no tempo, a História não se completa nunca, pois está em processo. Por consequente, indicar-lhe uma meta ou assinalar-lhe uma unidade perfeita significaria o fim da História. Com efeito, todas as representações da unidade são ideias e se engana quem quiser olhá-las como mais do que isso. Assim é, porque o Uno transcende a origem e a meta da História, caracterizando o problema como questão filosófica fundamental, que envolve a noção de realidade.

Palavras-chave: História. Filosofia. Eixo. Totalidade. Tempo.

Abstract: This article examines how Jaspers addresses the whole of history and the importance of the issue. It clarifies that attempts to establish such a unity by empirical facts are doomed to failure, because wholeness can only be sought as spiritual reality, or the creation of man. Thus considered, wholeness is the

\footnotetext{
* A pesquisa para este trabalho contou com a colaboração das alunas Thais Caroline Reis de Ávila e Edna Rogéria Durães Queiroz no contexto do programa PIBIC, financiado pela FAPEMIG. ** Doutor em Filosofia pela Universidade Gama Filho, Rio de Janeiro (1990) com estágios de pós-doutorado na Universidade Nova de Lisboa (1994) e na Universidade Federal do Rio de Janeiro (2010; professor no Centro Universitário Presidente Tancredo de Almeida Neves UNIPTAN, São João Del Rei, MG, e professor titular aposentado da Universidade Federal de São João Del Rei. Artigo recebido em 07/11/2017 e aprovado para publicação em 08/01/2018.
} 
result of the communication between human beings. It means that, as a human journey in time, history is never completed, since it is in process. Therefore, indicating a goal or a perfect unity would mean the end of History. Indeed, all the representations of unity are ideas and should not be considered otherwise. This is so because the One transcends the origin and goal of History, characterizing the problem as a fundamental philosophical question that involves the notion of reality.

Key-words: History. Philosophy. Axis. Totality. Time.

\title{
1 Considerações iniciais
}

\begin{abstract}
A o examinar a História como totalidade, o propósito de Karl Jaspers é lançar luzes sobre o homem, o grande problema de nosso tempo. ${ }^{1}$ Isso porque História como um todo é registro do percurso humano no tempo e não há como compreender o homem, ou considerá-lo como existente concreto ${ }^{2}$ sem considerar essa trajetória. Ao propor o problema dessa maneira, Jaspers apontou a consciência histórica como uma das mais importantes descobertas modernas. ${ }^{3}$ Quando abordamos a realidade do homem fala-se do modo como as coisas existem para ele. ${ }^{4}$
\end{abstract}

\footnotetext{
${ }^{1}$ Os existencialistas indicam que esclarecer o que é o homem era o grande desafio a ser enfrentado no século passado. Comenta Garaudy (GARAUDY, R. Perspectiva do Homem, 1966, p. 47): "A preocupação constante do existencialismo é reencontrar o homem existencial, o de nossa experiência pessoal, vivida, e de restaurar o contato íntimo, na existência humana, entre a subjetividade e a transcendência". Algo parecido diz Ortega y Gasset (ORTEGA Y GASSET, J. El tema de nuestro tempo, 1994, p. 178): "o tema de nosso tempo consiste em submeter a razão à vitalidade, localizá-la dentro do biológico, sujeitá-la ao espontâneo".

${ }^{2}$ Ele explica no terceiro capítulo de seu livro sobre a fé filosófica que o homem concreto é o que lhe confere valor (JASPERS, Karl. La fé filosófica, 2003b, p. 71): “o valor peculiar do homem não está na espécie ou tipo a que se aproxima, mas no indivíduo histórico irrepresentável e insubstituível'.

${ }^{3}$ Jaspers explicou no texto sobre a História no ensaio Sobre el espíritu europeo que os movimentos da história são entendidos com a consciência histórica. (JASPERS, Karl. Balance y Perspectiva, 1953b, p. 172): "não pode existir verdadeira história se não existe um saber sobre a História". ${ }^{4}$ Gadamer avaliou essa descoberta como se segue (GADAMER, H.G. O problema da consciência histórica, 1998, p. 17): "A aparição de uma tomada de consciência histórica é, possivelmente, a mais importante revolução por que passamos desde o surgimento da época moderna. O seu alcance espiritual ultrapassa, provavelmente, aquele que reconhecemos às realizações das ciências da natureza, as quais transformaram, de forma bem visível, a face do planeta. A consciência histórica, que caracteriza o homem atual, é um privilégio, talvez, mesmo um fardo tal como nenhum outro que tenha sido imposto a alguma das gerações anteriores".
} 
Essa forma de abordar a consciência como construção temporal mostrou ser imprescindível tratar a totalidade da História para entender a sociedade e o modo de vida de nossos dias. Essa forma de pensar começou a ser estruturada no século XIX pelas filosofias historicistas do idealismo alemão e do positivismo comtiano. O século XIX procurou entender as grandes civilizações que, na antiguidade, criaram a escrita e construíram sociedades complexas.

O esforço para entender o registro temporal da presença humana depois da escrita data de menos de seis milênios; é anterior à formação da consciência histórica de que fala Gadamer no século passado ou do esforço dos idealistas no anterior. Ela remonta às cosmogonias da antiga Grécia e também aos livros do Primeiro Testamento da Bíblia. ${ }^{5}$ A intenção igualmente se observa, alguns séculos depois, nos tratados da patrística quando se fez o confronto revelação e história, procurando entender os acontecimentos históricos e a razão das infelicidades históricas.

A esses motivos gerais para fundamentar essa investigação, Jaspers aponta um que parece essencial, a forma como se pensa a história afeta a compreensão da realidade e pode servir de justificativa para realidades indesejadas: "A imagem da história se converte em fator de nossa vontade, pois a maneira como pensamos limita nossas possibilidades, ou nos sustenta por seus conteúdos ou nos desvia tentadoramente de nossa realidade". ${ }^{6}$ Esse é um argumento decisivo para justificar o estudo do problema e conferir-lhe atualidade. A responsabilidade diante das crises históricas se fortalece com a consciência histórica. ${ }^{7}$

Esse trabalho se baseia principalmente no grande livro que Karl Jaspers dedicou ao assunto: Origen y meta de la Historia. No entanto, história como totalidade foi tema de outros trabalhos que merecem ser lembrados: o capítulo segundo da Introdução ao pensamento filosófico, a terceira conferência de A fé filosófica, o capítulo 9 da Iniciação Filosófica, no ensaio sobre o espírito europeu em Balance e Perspectiva, no quarto capítulo do segundo livro de Filosofia, no livro A bomba atômica e o futuro do homem. De modo indireto é assunto que percorre todo seu pensamento filosófico.

\footnotetext{
${ }^{5}$ No ensaio Sobre o espíritu europeo, Jaspers esclarece que o entendimento dos fatos depende de como se avaliam os acontecimentos. Os judeus, por exemplo, relatam nas histórias do Primeiro Testamento como enfrentar as infelicidades históricas e superá-las (JASPERS, 1953b, p. 172): “Nisso podem os judeus servir de exemplo aos europeus. ... o azar não é caso de insensibilidade num destino cego, mas uma infinita energia de aspiração".

${ }^{6}$ JASPERS, Karl. Origen y meta de la Historia, 1953, p. 247.

${ }^{7}$ No livro sobre a bomba atômica, o filósofo comenta a crise histórica que se vivia e a responsabilidade que ela produziu (JASPERS, Karl. A bomba atômica e o futuro do homem, Rio de Janeiro, Agir 1958. p. 28): “a maneira pela qual respondemos à possibilidade real de destruição decidirá a vida ou a morte da humanidade. A situação provoca uma responsabilidade que só se pode tornar consciente por meio de uma sinceridade absoluta".
} 
O método empregado na pesquisa é o analítico. Consiste em procedimento utilizado nos estudos filosóficos, sendo eficaz para clarear aspectos do pensamento do filósofo para explicitar suas ideias, reconhecer méritos e eventuais dificuldades. Sua utilização tem sido crescente nos estudos filosóficas. O Dicionário de Filosofia explica que: "Na cultura moderna e contemporânea, a tendência analítica, isto é, a tendência a reconhecer a análise como método de investigação estendeu-se e manifestou-se fecunda" ${ }^{8}$ O que faz a análise? Examina as partes de um todo, para conhecer sua natureza, funções e relações, isto é, chegar à determinação dos elementos que se organizam numa totalidade dada ou a se construir. No caso, o problema investigado é a compreensão do filósofo alemão Karl Jaspers sobre a História e sua importância como elemento de compreensão do mundo e enfrentamento das dificuldades humanas.

\section{As tentativas de explicação causal para uma história universal}

Jaspers parte do fato de que a totalidade da História é um problema filosófico. Ele apresenta algumas razões para essa afirmação. A principal é que os fatos históricos não revelam clara conexão entre si e por isso as tentativas de explicar a interferência ou vínculo entre as sociedades e fatos é cientificamente insuficiente. $\mathrm{O}$ contrário parece verdade, mesmo sem utilizar a noção de causa das ciências da natureza, a história dos povos revela conexões entre acontecimentos. Esclarece o filósofo: "De muitos paralelismos históricos se pode afirmar que deixam ver uma regra que se refere exclusivamente a fenômenos isolados". ${ }^{9}$

O problema não é simples: Se temos uma História, que condições produzem mudanças de alcance universal, qual é a explicação para a emergência de fenômenos amplos de sentido global. Por exemplo, o que faz surgir as grandes civilizações no Oriente Médio, na Índia e na China?

As tentativas dos cientistas de explicar a origem da História não parecem críveis. Esse tempo onde a História estabelece dimensões universais Jaspers denomina eixo. A mais importante das explicações propostas é a que atribui a presença de condições semelhantes no surgimento das grandes civilizações na Europa e Ásia, incluindo chineses e semitas, além dos indo-europeus. Essa teoria foi formulada por Alfred Weber e estaria relacionada à capacidade de estabelecer grandes deslocamentos da população e ao

\footnotetext{
${ }^{8}$ ABBAGNANO, Nicola. Dicionário de Filosofia, 1982, p. 49.

${ }^{9}$ JASPERS, 1953, p. 18.
} 
surgimento de experiências de desalento face às guerras e a catástrofes nascidas desses deslocamentos. O filósofo assim a resume:

A irrupção de povos que usavam carros de guerra e depois de cavaleiros saídos da Ásia Central - que de fato alcançou China, Índia e Ocidente. (...). Os homens desses povos tiveram, graças ao cavalo, a experiência da amplitude do mundo. Tornaram-se senhores de antigas culturas. Com os azares, os riscos e as catástrofes também o problematismo da existência e o desenvolvimento de uma consciência trágico-heróica, que encontrou expressão na épica. ${ }^{10}$

Os grandes deslocamentos dos grupos de cavaleiros guerreiros os levaram a enfrentar os grupos estabilizados de organização matriarcal que viviam sedentários em pequenos espaços. $\mathrm{O}$ resultado desses embates foi a ampla vantagem dos cavaleiros guerreiros. Aos poucos esses grupos passaram a ocupar o espaço das sociedades matriarcais pacíficas e sedentárias. Essa explicação para a construção da História como fenômeno universal foi assim avaliado por Jaspers (id., p. 23): “a tese de Weber possui uma força iluminadora por sua singela explicação causal, partindo do caráter humano a existência nômade. No entanto, não se refere ao cerne mas a uma condição."11 As migrações não são desconhecidas na história do homem, mas nenhuma delas produziu o desenvolvimento espiritual que ganhou corpo nesse chamado tempo eixo. ${ }^{12}$ Fica-se por entender como o desenvolvimento espiritual ocorreu no mesmo período e em povos distantes com forte impacto até nossos dias.

Diante da insuficiência da tese de Weber, Jaspers revisa a hipótese do surgimento de uma condição geral, isto é, de uma organização sociológica favorável ao desenvolvimento espiritual. Isso viria da emergência de muitos pequenos estados, de variadas cidades e da emergência de disputas políticas internas. A hipótese de que certas condições sociológicas são fundamentais para o surgimento das grandes realizações do espírito e a mais excelsa delas que é a atividade filosófica foi sugerida por Aristó-

\footnotetext{
10 JASPERS, 1953, p. 22.

${ }^{11}$ JASPERS, 1953, p. 23.

${ }^{12}$ Anselmo Borges comentou o significado desse tempo eixo do seguinte modo (JASPERS, K. Os mestres da humanidade, 2003, p. 8): "Para Jaspers, durante o primeiro milênio antes de Cristo, mais concretamente por volta do século VI, época conhecida como tempo eixo, deu-se uma transformação essencial na consciência humana em áreas geograficamente distantes e aparentemente sem interferência: Índia, China, Pérsia, Grécia e Israel. O homem passou de uma consciência predominantemente cósmica a uma consciência reflexiva, de uma consciência submersa no grupo e na coletividade a uma consciência de identidade individual e pessoal. Foi também nesse quadro que emergiu uma decisiva transformação religiosa, com a necessidade e a procura da salvação pessoal, com o aparecimento das religiões universais e uma mudança na concepção do divino, com três orientações fundamentais; o monismo, o monoteísmo, a exigência crítica e racional na sua representação. É dessas correntes que ainda hoje vivemos".
} 
teles e adotada por Georg Hegel..$^{13}$ No entanto, Jaspers contrapõe a essa explicação, a saber, que as condições sociológicas e históricas amplas, ou a emergência de determinadas conquistas materiais desse tempo permitiram a preocupação com o universal, a afirmação de que essas condições fazem parte desse tempo e não são causa dele. O desafio é: "descobrir o fato que produz essa grande crise, capturá-lo em seus múltiplos aspectos, interpretá-lo em sua significação, para deixá-lo provisoriamente ante nossos olhos como um mistério crescente" ${ }^{14}$ Parecendo inútil procurar as causas do tempo eixo, o filósofo se pergunta pelo sentido desse tempo. Será possível encontrá-lo?

\section{3 o sentido do tempo eixo}

Ao invés de insistir naquilo que não leva ao conhecimento das causas do surgimento do tempo eixo, nosso pensador se propõe a investigar se é mais adequado perguntar-se pelo sentido ou significado desse tempo. A descoberta desse sentido seria fundamental porque: "poder-se-ia apreender algo que é comum a toda a humanidade, por cima de todas as discrepâncias de crenças religiosas". ${ }^{15}$ Esse significado é diverso do que demonstra ter o crente quando pensa, à luz da fé, a unidade da história. Já vimos que tempo eixo se dá entre os anos 800 e 200 a. C. e que ele é um momento em que a História se faz visível para todos os homens. E assim é porque Ocidente, Índia e China, mesmo sem contato entre si, alcançam um nível de desenvolvimento espiritual incomparável com tudo o que existia e arrastam todos os homens nesse processo.

Essa tríplice origem do tempo eixo sugere a comunicação entre os grupos para aprofundar a compreensão do processo. $\mathrm{O}$ reconhecimento desse tempo eixo, entre os anos 800 e 200 a. C. não significa que o período que o antecedeu não tenha relevância ou que o que veio depois não representou significativa mudança em relação ao que ali foi feito? Jaspers esclarece que não se trata disso, não significa dizer que Homero é menor que Virgílio, Augusto que Sólon ou Jesus que Jeremias. O que ocorreu fora desse tempo eixo tem valor, o passado enquanto revelador da origem comum

\footnotetext{
${ }^{13}$ Eis como Hegel defendeu essa tese (HEGEL, G. W. F. Introdução à história da filosofia, 1988. p. 119/120): "Note-se, antes de mais nada, que se requer num povo certo grau de cultura intelectual para que se possa filosofar. Diz Aristóteles que o homem começa a filosofar depois de ter provido as necessidades da vida. Visto a Filosofia ser atividade livre, não egoística, e sobrevir com o desaparecimento das angústias e necessidades, o espírito deve estar temperado, elevado e revigorado em si mesmo. Importa que as paixões se encontrem adormecidas, e que a consciência tenha progredido a ponto de poder pensar o universal". ${ }^{14}$ JASPERS, 1953, p. 24.

${ }^{15}$ JASPERS, 1953, p. 25.
} 
e o futuro com novas realizações. O fundamental do tempo eixo é que nele se estabelecem elementos para uma história universal e fundamentos espirituais utilizados até hoje. $\mathrm{O}$ que isso significa encontra-se resumido na Iniciação Filosófica:

Quinhentos anos a. C. entre o ano oitocentos e o de duzentos deu-se a colocação dos fundamentos espirituais da humanidade de que esta se tem alimentado até hoje, e isso aconteceu simultânea e independentemente na China, na Índia, na Pérsia, na Palestina e na Grécia. ${ }^{16}$

O que chamamos de História é um período curto se comparado aos séculos em que o homem está na terra, algo como seis mil anos. Esse é o tempo com registro escrito das civilizações. Embora Jaspers fale de uma História universal isso não significa que as sociedades de outros tempos não tivessem vida própria ou interagissem. O que ocorre então é que ao entrar em contato entre si elas se modificaram ou ficaram perturbadas com o que descobriram.

Jaspers divide a História em quatro grandes momentos: o inicial quando o homem começou a falar, aprendeu a utilizar o fogo e inventou os primeiros utensílios; o segundo entre cinco mil e três mil a. C. quando nasceram as grandes civilizações do Egito, Mesopotâmia, Índia e China; o terceiro é o tempo eixo já especificado e o último o momento final da Idade Média quando surge a ciência moderna.

O tempo eixo, fundamental para a articulação da ideia que Jaspers constrói da História, ao originar as construções espirituais do homem e permitir a emergência de uma História universal ensina que o homem tem algo que recebe por herança, seu corpo por exemplo e outra parte que vem como tradição. E tradição é diferente do que se herda de antigas gerações, tem valor, pode ser ampliado ou se perder. Explica o filósofo

O começo da história, adquirido desde a pré-história, existe por assim dizer, um capital do ser humano que não é herdado biologicamente, mas como substância histórica, um capital que pode ser aumentado ou perdido. É algo que é real antes de todo pensar, que não se pode fazer nem produzir de propósito. ${ }^{17}$

A descoberta do valor e peso da tradição cultural significa que a história humana é diversa do que se chama de história da natureza ou do cosmo. A história humana é cheia de novidade e inovação e não segue uma sequência regular e causal. A história do homem representa a evolução de uma consciência pensante que se reconhece ela própria totalidade e consciência do mundo. Embora tal consciência que nele se desenvolveu

${ }^{16}$ JASPERS, Karl. Iniciação Filosófica, 1987, p. 91.

${ }^{17}$ JASPERS, 1987, p. 255. 
seja um fenômeno mínimo, quando comparado à grandeza e imensidão do universo, não deixam de ser um fato inteiramente novo que ocorreu no universo.

\section{Estrutura e unidade da história}

No item anterior indicou-se que a História do homem é fenômeno único no universo, diferente das mudanças regulares da natureza. Também distinguiu-se seu estudo da metodologia empregada nas ciências da natureza, pois o exame de causas e leis necessárias não traduzem a unicidade da História, que só é apreensível como ideia. Erramos, portanto, se tentamos pensar a História a partir de elementos gerais.

Agora cabe destacar que é na História que se entende o que é o homem enquanto liberdade, como quem constrói a vida nas escolhas que faz. Diz o filósofo: "é na História que nos encontramos a nós mesmos em forma de liberdade, de existência, de espírito, de gravidade, na decisão, de independência do mundo." 18

Nesse homem que se deixa ver na História, Jaspers descobre o amor como realidade fundamental, amor em sentido amplo que se mostra de muitas formas e que se estende até o Ser e à origem do homem. Portanto, o amor é a mola que Jaspers encontra para realizar a investigação da origem. É essa relação com o Ser total e a origem que ajuda a escolher os temas a investigar e distinguir o fundamental do relativo.

Ao introduzir o problema do Ser como totalidade que inspira a investigação da História, Jaspers desenvolve uma ontologia e se transporta para o universo filosófico. Na unicidade dos fatos, ele descobre o movimento que caracteriza a História. Daí esclarece que o entendimento do Ser da História é sempre o conhecimento simultâneo da mudança e unicidade, ainda que se tenha a ilusão do regular. O homem não vive no imutável, esclarece: "a profundidade do movimento de uma transição aporta a suma claridade do Ser e da verdade. A degeneração e debilitamento da transição, que se produz na enganosa duração de uma persistência, (...) fazem supor a repetição extrínseca no costume e na natureza". ${ }^{19}$ Quando julgamos encontrar o Ser da História nos acontecimentos, do mesmo modo que quando julgamos haver encontrado a verdade definitiva que explica a realidade, apenas nos iludimos. Aqui se revela a influência kantiana na compreensão dos limites da razão, embora ela esteja em permanente

18 JASPERS, 1987, p. 260.
${ }^{19}$ JASPERS, 1987, p. 262. 
tensão entre o que procura e o que encontra. Se o homem não consegue apreender a totalidade não pode prescindir dessa busca, sob pena de ficar no imediato que falsifica mais que revela o real. Nesse sentido, todas as grandes referências sobre o homem no tempo e sobre seu entendimento da realidade revelam algo importante quando apontam o caráter transitório da vida e das realizações humanas. E também quando permitem entender o passado como referência para o futuro.

Quando se mergulha na tensão entre a transitoriedade e totalidade da História descobre-se relação semelhante à encontrada no Ser do homem. $\mathrm{O}$ homem se conhece como fenômeno e se experimenta como liberdade, revelando a tensão entre o transitório e a totalidade na sua condição existencial. ${ }^{20} \mathrm{E}$ há ainda outra tensão, o homem é parte de uma humanidade comum, mas que somente aparece como ideia, pois o que há de concretamente observável é a singularidade existencial, ou a unicidade de cada sujeito humano. O homem tem aspectos comuns na sua herança corporal, aspectos psicológicos ou na sua organização social, mas isso que é natural do homem não é o que o caracteriza essencialmente. O comum não basta para explicar o que o homem é enquanto sujeito singular. Diz o filósofo (id., p. 270): “o que é universal não pode constituir a verdadeira unidade dos homens" ${ }^{21}$ Assim, quando se busca a origem o que importa não é determinar como o corpo evoluiu, mas como se desenvolveu no homem o que o singulariza. E esse aspecto essencial, que olhado na origem, aponta para a divindade. Isso significa que quando se pensa a origem toca-se uma cifra. O filósofo parece usar o conceito no sentido matemático, onde o algarismo zero (cifra) não tem valor em si, mas confere valor quando associado a outros algarismos. Nessa ontologia cifra é, portanto, a referência de algo que não se deixa ver em si, mas confere valor ao que aparece como objeto.

O século XIX consagrou a categoria progresso como forma de traduzir os movimentos da História. O progresso enquanto acréscimo de sucessivas práticas complementares é observável na história da técnica, mas não na História dos homens. Essa não é para o filósofo uma categoria adequada para tratar da História. Muitos povos que alcançaram alto grau de desenvolvimento e organização foram destruídos por povos bárbaros. Comenta Jaspers: "A aniquilação física do tipo humano superior pela esmagadora realidade das massas é um fenômeno básico da história". ${ }^{22} \mathrm{E}$ os povos que alcançaram notável desenvolvimento não asseguraram a transmissão do seu legado.

\footnotetext{
${ }^{20}$ Jaspers comentou essa tensão como se segue (JASPERS, K. Introdução ao pensamento filosófico, 1993, p. 48): “Todo conhecimento que o homem tem de si diz respeito a fenômenos, as suas condições e potencialidades. O homem não se identifica a qualquer desses aspectos, porém os incorpora ao longo da jornada que o leva si mesmo".

${ }^{21}$ JASPERS, 1987, p. 270.

${ }^{22}$ JASPERS, 1987, p. 271.
} 
Quanto a expansão de práticas, técnicas, línguas e conhecimentos pode-se observar que o fenômeno era comum em vários continentes. Esse fenômeno foi constatado na América, na Ásia, na África, além, é claro, da Europa. Tal expansão cultural constituiu unidades relativas. A universalização de práticas compartilháveis entre todos os continentes ganhou efetividade no século XV quando os europeus levaram para todos os cantos da terra o seu modo de vida. Então a ampliação que se observava no interior dos continentes ganhou força. Diz o filósofo: “Desde o século XV, os europeus colocaram o planeta inteiro em sua rede de comunicações. Levaram sua civilização a todas as partes e se apropriaram de bens da civilização que não possuíam". ${ }^{23}$ Ele identifica, nesse instante, a formação de unidades especiais que aproximam elementos culturais, mas que disputam entre si e tentam se sobrepor umas às outras.

Se a unidade da História não é fato e não pode ser apreendida por uma teoria, poderia ser entendida como meta a ser alcançada? Algumas metas já foram tentadas como, por exemplo, a humanização do homem, que corresponde a expressão pelo espírito de conhecimento e valores; pelo exercício da liberdade; pela formação do homem superior ou finalmente, pelo propósito metafísico do descobrimento do Ser do homem. Para Jaspers, todas essas metas foram parcialmente alcançadas e perdidas ou em suas palavras: "todas as gerações as realizam a sua maneira". ${ }^{24}$ Apesar dessa realização parcial, as diferentes gerações têm a pretensão de identificar o sentido último, de dar a última palavra sobre o assunto, mas falham e deixam para a seguinte a missão de recomeçar o trabalho.

Esse sentido foi buscado no decorrer do tempo de duas formas, ou pela revelação divina ou pela razão. $\mathrm{O}$ impacto que a ideia de revelação teve na consciência ocidental foi profunda. Essas ideias integraram o texto bíblico, depois se misturaram com os propósitos da razão e foram laicizadas. Jaspers consegue estabelecer essa sequência como se segue (id., p. 278):

Os que primeiro o pensaram foram os profetas judaicos, depois o problema encontrou forma cristã em Santo Agostinho, foi repetido e perdeu força desde Joaquim de Fiore até Bossuet, e secularizado mais tarde desde Lessing e Herder até Hegel, é sempre o saber acerca de uma história total em que o todo tem o seu lugar marcado. Dele salta à vista uma série de princípios fundamentais que, compreendidos em toda sua profundidade, nos ensinam o que propriamente existe e acontece. Porém tais construções - tão grandiosamente expressas e criadas em dois mil anos de história - soçobraram. ${ }^{25}$

Descobrir o sentido da História fracassou por duas razões: a referência à totalidade desconsidera o papel dos indivíduos concretos, cujo valor e

\footnotetext{
${ }^{23}$ JASPERS, 1987, p. 273.

${ }^{24}$ JASPERS, 1987, p. 277.

${ }^{25}$ JASPERS, 1987, p. 278.
} 
significado somente ganham força se inseridos nessa realidade total e nessa história construída por teólogos e filósofos muitos povos ficaram fora e não protagonizam nada. Essas duas afirmações levam à seguinte conclusão: "a totalidade da história, (...) não se apresenta nem verdadeiramente como visão, nem como realidade, nem como sentido." ${ }^{26}$

Apesar da insuficiência dos esforços permanece válida a ideia de uma História universal. O filósofo elenca cinco razões para justificar: 1. Mesmo sem possibilidade de sucesso completo, a ideia de unidade da história orienta as tentativas de sucesso parcial; 2 . O planeta é limitado e circunscreve espacialmente o lugar onde vive o homem; 3 . Os homens possuem uma forma universal de pensar, o que remete à consciência transcendental de Kant; 4. A ideia de unidade está presente em todas as tentativas da razão de alcançar as verdades fundamentais e 5 . Mesmo que não se alcance uma visão definitiva dessa unidade há formas que mostram imagens desse todo, por exemplo: "A história vista na hierarquia de valores, em suas origens, em seus passos decisivos". ${ }^{27}$

\section{A consciência histórica do tempo em que viveu}

O homem sempre recebeu informações das gerações passadas, mas o assunto ocupou historiadores e filósofos na antiguidade clássica. Esse esforço ganhou uma dimensão crítica no século XIX quando se formularam diversas teorias sobre a História, muitas com pretensão de cientificidade. Essa forma de enxergar do século XIX foi posta sob suspeita no século passado. Isso se deveu a uma nova metodologia histórica que associou fatores causais, categorias amplas de ciências complementares, estruturas morfológicas, leis de sentido e teorias. Trata-se de uma multidão de informações vindas de diferentes ciências e também da revisão crítica das últimas teorias históricas. Nesse esforço, destacam-se as teorias de Max Weber e Leopold von Ranke. Esse último estabeleceu a metodologia consagrada pela ciência histórica, introduzindo elementos de metodologia investigativa como o uso prioritário de fontes primárias e destaque da narrativa histórica.

Jaspers aprofunda a noção de consciência histórica no capítulo V de Filosofia. Ali explica que consciência histórica é uma forma especial de saber da História que combina a presença física do homem e a circunstância onde ocorre. Isso leva ao reconhecimento de que fatos históricos são únicos e irrepetíveis. Ele afirma: "Essa consciência se faz patente na imagem

${ }^{26}$ JASPERS, 1987, p. 280.

${ }^{27}$ JASPERS, 1987, p. 281. 
panorâmica de uma história universal e na capacidade - sempre limitada - de interpretar pelo passado o que existe hoje." ${ }^{28}$

Logo, Jaspers entende que não é necessária uma totalidade perfeitamente descrita para assegurar seu valor. A imperfeição da abordagem não inutiliza o esforço de procurar a totalidade da história e de descobrir nas diversas teorias, se não uma explicação definitiva, elementos para esclarecer a realidade em que se vive.

A consciência histórica contemporânea entende que a noção de história e o presente são inseparáveis, o que significa que cada geração olha o passado de forma diferente. Cada vez que se olha a história esse olhar ilumina o presente de forma renovada e revela quem eu sou. E essas duas dimensões da consciência se completam e interagem, a imagem da História e a consciência atual. A forma como vejo o passado é a mesma como percebo o presente.

Finalmente, a História como totalidade permite que se projete uma realidade que está além dos fatos vividos por que remete a uma origem que vai para além dos fatos.

Se não se consegue uma formulação perfeita da totalidade histórica, há situações que projetam a superação da compreensão histórica. São as seguintes os momentos em que isso ocorre: 1. Quando se mergulha no ritmo regular da natureza; 2. Quando se formula a noção de verdade eterna que independe da História; 3. Quando se propõe o presente eterno como o lugar que transcende a História e lhe dá significado. Esclarece o filósofo: "o que é eterno aparece como decisão no tempo. Pela consciência transcendente da existência se desvanece a História no eterno presente" ${ }^{29} 4$. Quando se descobre o inconsciente que não propicia experiência do mundo, pois a percepção somente pode se dar de forma consciente. $\mathrm{O}$ inconsciente que sustenta a existência é tanto a natureza, como é aquilo que se encontra no espírito, mas ainda não está revelado, não emergiu na consciência. 5. Se supera a compreensão histórica quando se consegue uma referência mais elevada do Ser além do horizonte do tempo. 6. Quando se percebe a extensão da pré-História e a pequena extensão temporal do tempo histórico.

\section{Considerações finais}

Quando pensa a totalidade da História, Jaspers dialoga com Edmund Husserl e Immanuel Kant. Por influência desse último reconhece a imanência dos mecanismos da consciência no conhecimento do mundo. Em

\footnotetext{
${ }^{28}$ JASPERS, Karl. Filosofía., 1968, p. 525.

${ }^{29}$ JASPERS, 1987, p. 295.
} 
outras palavras, o filósofo assume que o que se pode conhecer é do que se tem experiência e ficou na consciência. ${ }^{30}$ Jaspers comentou em Filosofia de la existencia: "Kant compreendeu que o mundo nunca se torna objeto para nós, mas é sempre só uma ideia; quer dizer, que tudo que podemos conhecer está no mundo, mas não é o mundo". ${ }^{31}$ Assim, quando examina alguma totalidade, avalia o filósofo acompanhando Kant, a consciência pretende tratar do que não se torna objeto, mas transcende a capacidade humana de conhecer. Esse aspecto ainda que incognoscível é fundamental para avaliar o momento em que se vive. ${ }^{32}$

O modo de pensar filosoficamente, permanecendo no limite da consciência intencional, mas se abrindo ao que de fora a ilumina, marca seus estudos sobre a História como totalidade, é próprio do filósofo. Para explicá-lo elaborou o conceito de englobante que é central em sua filosofia. Englobante se refere ao de onde provêm o que surge como objeto da consciência: "a operação filosófica fundamental transforma minha consciência do ser. $\mathrm{O}$ ser em sua totalidade não é compreensível conceitualmente mediante uma ontologia, mas só é concebível como espaço englobante e como o espaço em que nos vêm todos os seres". ${ }^{33}$

Quando estudamos esses textos de Jaspers precisamos considerar, como pano de fundo, a compreensão de englobante, pois a totalidade histórica não é objeto da ciência, mas da Filosofia. Para abordá-la o filósofo utiliza o mesmo raciocínio empregado para resolver outros problemas: a tensão entre o que é englobante e o que se apresenta à consciência. No exame desse problema ele diz ser necessário ir além dos tempos históricos até a origem do homem para pensar a totalidade.

Nesse estudo fica indicado a relação entre a Filosofia e a Ciência, assunto que Jaspers cuida sempre. Para remontar à origem do homem, o filósofo não prescinde das descobertas do historiador ou de outras ciências. Parte desses estudos, mas como visa a totalidade, precisa de mais do que o historiador ou cientista pode oferecer com a metodologia que utiliza.

\footnotetext{
${ }^{30}$ Na Estética Transcendental, comentou Kant (KANT, E. Crítica da Razão Pura. v. I, 3. ed., 1987, p. 39): "Portanto, pela sensibilidade nos são dados objetos e apenas ela nos fornece intuições; pelo entendimento, ao invés, os objetos são pensados e dele se originam conceitos. Todo pensamento, contudo, quer diretamente, quer por rodeios, através de certas características, finalmente tem de se referir a intuições, por conseguinte em nós à sensibilidade, pois de outro modo nenhum objeto pode ser-nos dado".

${ }^{31}$ JASPERS, Karl. Filosofía de la existencia. Madrid, Aguillar, 1961, p. 47.

${ }^{32}$ Esse aspecto foi comentado do seguinte modo (HERSCH, Jeanne. Karl Jaspers, 1982, p. 55): "Se a referência à trans-histórica é indispensável à História, ela não subtrai nada ao instante presente em que a existência situada se decide em face da transcendência. Ao contrário: é a trans-história que dá à existência a sua historicidade e à unicidade a cada instante, hic et nunc, o seu valor absoluto".

${ }^{33}$ JASPERS, Karl, 1953, p. 49.
} 
Por considerar a totalidade de História uma ideia parece-lhe impossível aventar um fim ou sentido último para ela, embora, pareça-lhe que a História tenda para um relativo aperfeiçoamento, o que é uma contradição com a qual ela convive.

Jaspers justifica coerentemente a importância de pensar a totalidade dos fatos históricos, pois é isso que permite compreender o passado e avaliar melhor a relação entre os fatos..$^{34}$ Entretanto, ao fazer tal avaliação ele está longe de interpretar o passado com a consciência presente. Com todas as limitações dessa tarefa, o homem não pode prescindir desse esforço porque o que se pensa ser o mundo é o modo como as coisas existem para quem assim pensa. Assim, embora no ocidente essa amarração dos acontecimentos tenha sido feita pelo cristianismo, parece-lhe fundamental estabelecer um nexo racional que permita esse reconhecimento universal. Isso permitirá aos homens de diferentes gerações e culturas reconhecer a dimensão transcendente da História. ${ }^{35}$

Apesar de perceber o movimento de globalização do ocidente, Jaspers ainda não percebera, nos dias que viveu, a mundialização dos processos produtivos. Porém entende que no mundo que se formava fortaleciam-se as unidades especiais, diríamos de Estado ou regiões maiores, onde a experiência histórica do tempo tinha configuração singular. Ele não fala de blocos econômicos, que também não existiam até meados do século passado, nem da tensão que se estabelece na tentativa de defender, certo modo de vida, nessas unidades especiais. Porém ele parece antever, no século passado, o fortalecimento dos propósitos da direita radical que hoje ganha força em diversas nações do mundo. Esses grupos, apesar de agendas locais, querem isolar essas unidades num mundo onde a universalização aponta para outra agenda. As observações do filósofo sobre unidades especiais no interior da humanidade traduzem a tensão entre o que pode ser universalizado e o esforço de elementos que querem permanecer singulares.

Adicionalmente, na medida em que a consciência histórica é esclarecida e caracterizada, essas teses ajudam: a superar os historicismos do século XIX, a compreender os desafios atuais para pensar a História e também a apontar o valor da filosofia num tempo em que ela é pouco considerada.

\footnotetext{
${ }^{34}$ Ele afirmou no capítulo 9 de um dos seus livros (JASPERS, 1987. p. 89): "A experiência do presente compreende-se melhor refletida no espelho da história. O que a história nos transmite vivifica-se à luz da nossa época. A nossa vida processa-se no esclarecimento recíproco do passado e do presente".

${ }^{35}$ Essa questão foi examinada como transcrito (CARVALHO, José Mauricio de. Filosofia e Psicologia, o pensamento fenomenológico existencial de Karl Jaspers. 2006, p. 67): “Para o filósofo aprender com a História é fundamental, mas é necessário ir além dela, pensar através dos fatos e buscar a eternidade. Apesar dos condicionamentos de cada época inerentes à reflexão, não é a partir da circunstancia que pensamos, mas do englobante. Está nele a razão funda de tudo o que realizamos".
} 


\section{Referências}

ABBAGNANO, Nicola. Dicionário de Filosofia. 2. ed., São Paulo: Mestre Jou, 1982. 976 p.

CARVALHO, José Mauricio de. Filosofia e Psicologia, o pensamento fenomenológico existencial de Karl Jaspers. Lisboa: Imprensa Nacional, 2006. 265 p.

GADAMER, Hans Georg. O problema da consciência histórica. Rio de Janeiro: Editora FGV, 1998. 89 p.

GARAUDY, Roger. Perspectivas do homem. Rio de Janeiro: Civilização Brasileira, 1966. 355 p.

HEGEL, Georg Wilhelm Friedrich. Introdução à história da filosofia. 4. ed., São Paulo: Nova Cultural, 1988. p. 83-158.

HERSCH, Jeanne. Karl Jaspers. Brasília: Editora da UnB, 1982. p. 105

JASPERS, Karl. Origen y meta de la Historia. 2. ed., Madrid: Revista de Occidente, 1953. 307 p.

Sobre el espíritu europeo. In: Balance y Perspectiva. Madrid: Revista de Occidente, 1953b, p. 163-185. A bomba atômica e o futuro do homem. Rio de Janeiro: Agir 1958. 48 p. - Filosofía de la existencia. Madrid: Aguillar, 1961. 154 p. . Filosofía. Madrid: Revista de Occiddente; Puerto Rico, Universidad de Puerto Rico, 1968. 557 p. . Iniciação Filosófica. Lisboa: Guimarães, 1987. 159 p. . Introdução ao pensamento filosófico. 9 ed., São Paulo: Cultrix, 1993. 147 p. . Os mestres da humanidade. Apresentação de Anselmo Borges. Coimbra: Almedina, 2003. 165 p. . La fé filosófica. Buenos Aires: Losada, 2003b, 173 p.

KANT, Immanuel. Crítica da Razão Pura. v. I, 3. ed., São Paulo: Nova Cultural, 1987. $172 \mathrm{p}$.

ORTEGA Y GASSET, José. El tema de nuestro tempo. Obras Completas. $2^{\text {a }}$ reedición, v. III, Madrid: Alianza, 1994. p. 145-242.

Endereço do Autor:

Rua Resende Costa, 154

Centro Histórico - Largo da Cruz

36300-118 São João Del Rei - MG

josemauriciodecarvalho@gmail.com 